\title{
- Associação homem-animal: reflexos na economia
}

- The association between man and

\section{animal: economic repercussions}

* LuizCarlos deSouza ${ }^{1}$-CRMV-SP-n n $^{0} 1094$

Osni ÁlamoPinheiro Júnior ${ }^{2}$-CRMV-SP-n9473

Andréde 0liveiraMendonça ${ }^{3}$ - CRMV-SP-n ${ }^{0} 11399$

AmandadeLourdes Ballaris ${ }^{4}$-CRMV-SP-ñ10171

1 Prof. Ass. Dr. do Departamento de Higiene Veterinária e Saúde Pública - FMVZ - UNESP/Botucatu.

2 Pós-graduando na Area de Vigilância Sanitária - FMVZ - UNESP/Botucatu.

3 Residente (R-2) na Área de Zoonoses e Saúde Pública - FMVZ - UNESP/Botucatu.

${ }^{4}$ Pós-graduanda na Área de Vigilância Sanitária - FMVZ - UNESP/Botucatu.

\section{RESUMO}

Os animais domésticos representam, na atualidade, uma viga de sustentação econômica, uma vez que, apesar da crise financeira e das altas taxas de desemprego que o País enfrenta, o ramo de "pet shop" encontra-se em franca expansão. Desta forma, há um estímulo direto e indireto para obtenção de animais de estimação, fortalecendo a relação homem-animal. Nesse sentido foi realizado um trabalho de investigação epidemiológica no Município de Bauru-SP, a fim de verificar o impacto desses animais na economia doméstica e na do município. Para tanto, utilizaram-se fichas de investigação, entrevistas pessoais e pesquisas em clínicas veterinárias, com uma amostragem de 115 proprietários de animais, dos quais 91 de cães e 24 de gatos. Considerando-se custos com alimentação, abrigo, remédios, vacinas e visita ao veterinário, em condições ideais de manutenção dos animais, obteve-se um custo estimado de $R \$ 401,00$ e $R \$ 316,00$ para cães no primeiro e segundo ano de vida, respectivamente, e de $\mathrm{R} \$ 272,00$ e $\mathrm{R} \$ 232,00$ para gatos no primeiro e segundo ano de vida, respectivamente. Deve haver um esforço maior das autoridades e das instituições de ensino para esclarecer à comunidade a respeito do impacto econômico que um animal de estimação pode causar no orçamento familiar e também sobre a importância desses animais enquanto transmissores de importantes doenças para a saúde pública, a fim de popularizar o conceito de posse responsável de animais.

Palavras-chave: pequenos animais, mercado, economia.

\section{Introdução}

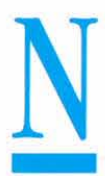

os últimos anos, tem-se observado, no cotidiano dos centros urbanos do Brasil e de outros países, uma verdadeira "explosão" do comércio de produtos agropecuários e, especificamente, de produtos direcionados aos animais de pequeno porte, tais como: cães, gatos, pequenos roedores e aves. Nesse sentido, nota-se que as empresas desse ramo comercial têm investido grandes quantias em pesquisas para a melhoria de seus produtos e propagandas, as quais estimulam indiretamente a obtenção de um animal de estimação, estreitando cada vez mais este vínculo homem-animal.

A AVMA (American Veterinary Medical Association) tem realizado estudos periódicos a respeito do crescimento da população de animais de estimação e do custo que estes trazem para as famílias 
SOUZA, L. C.; PINHEIRO JÚNIOR, O. A.; MENDONÇA, A. O.; BALLARIS, A. L. Associação homem-animal: reflexos na economia / The association between man and animal: economic repercussions. / Rev. educ. contin. CRMV-SP / Continuous Education Journal CRMV-SP, São Paulo, volume 4, fascículo 1, p. 62 - 65, 2001.

norte-americanas. Em um desses estudos, realizado em 1997, foram distribuídos 80.000 questionários, dos quais 59.998 foram respondidos. Pelas respostas obtidas, foi possível estimar que $58,9 \%$ das famílias americanas tinham, em 1996, pelo menos um animal de companhia, das quais $31,6 \%$ delas possuíam pelo menos um cão e $27,3 \%$ pelo menos um gato (GEHRKE, 1997a). Entre os anos de 1991 e 1996 , a população canina cresceu $0,8 \%$ e a felina $3,7 \%$. Em média, os proprietários de cães fizeram 1,80 visita ao veterinário com custo de US\$73,60/ visita em 1996 e os de gatos 1,01 visitas com custo de US\$66,58/visita (GEHRKE, 1997b). Estimou-se que, nesse mesmo ano, os proprietários de cães gastaram cerca de US\$7 bilhões com produtos e serviços veterinários, enquanto os proprietários de gatos gastaram US\$4 bilhões. Esses valores representam um aumento real de US $\$ 10,2$ bilhões no gasto com produtos e serviços veterinários para animais de companhia, entre 1991 e 1996, o que equivale a um crescimento de cerca de $4,3 \%$ ao ano nesse mercado (GEHRKE, 1998).

O presente trabalho teve por objetivos verificar o custo aproximado de manutenção dos principais animais de companhia no Município de Bauru-SP e avaliar o significado econômico desta associação para o município.

\section{Material e Método}

Os dados utilizados no presente trabalho foram obtidos do preenchimento de fichas de investigação epidemiológica pelos proprietários, os quais foram abordados em visitas domiciliares e a clínicas particulares, totalizando uma amostragem de 91 proprietários de cães e 24 de gatos. As informações relacionadas às atividades do Centro de Controle
Tabela 1. Custo estimado de manutenção ideal de cães e gatos nos dois primeiros anos de vida. Bauru-SP. 2000.

\begin{tabular}{|l|c|c|}
\hline \multicolumn{1}{|c|}{ Espécie } & \multicolumn{2}{|c|}{ Custo estimado (R\$) } \\
\hline & Primeiro ano & Segundo ano \\
\hline Canina & 401,00 & 316,00 \\
\hline Felina & 272,00 & 232,00 \\
\hline
\end{tabular}

de Zoonoses (CCZ) de Bauru foram obtidas por entrevista com o médico veterinário responsável pelo $\mathrm{CCZ}$.

\section{Resultados}

Na Tabela 1, constam os valores estimados do custo de manutenção ideal de cães e gatos nos dois primeiros anos de vida e, na Tabela 2 estão especificados os valores utilizados para esse cálculo. As Figuras 1 a 4 mostram a participação percentual de cada item avaliado e a Tabela 3 mostra os valores extrapolados para o total da população canina e felina do município, de acordo com os dados obtidos pelo censo realizado pelo $\mathrm{CCZ}$, e seus respectivos custos de manutenção.

\section{Discussão}

A literatura nacional é escassa em trabalhos que abordem os aspectos econômicos e comerciais relacionados à criação de animais de companhia. Essa abordagem é fundamental para que se conheça a dinâmica desse mercado e suas tendências para o futuro, o que interessa particularmente aos médicos veterinários que atuam no ramo. Trabalhos deste tipo são realizados pe-

Tabela 2. Valores utilizados para o cálculo do custo de manutenção ideal de cães e gatos nos dois primeiros anos de vida. Bauru-SP. 2000.

\begin{tabular}{|l|c|c|c|c|}
\hline \multirow{4}{*}{ Tipo de custo } & \multicolumn{3}{|c|}{ Valor estimado (R\$) } \\
\hline \multirow{3}{*}{ Abrigo } & \multicolumn{2}{|c|}{ Cães } & \multicolumn{2}{c|}{ Gatos } \\
\cline { 2 - 5 } Ração & Primeiro ano & Segundo ano & Primeiro ano & Segundo ano \\
\cline { 2 - 5 } Vermífugo & 35,00 & - & 20,00 & 168,00 \\
Combate a & 240,00 & 240,00 & 168,00 & 9,00 \\
ectoparasitas & 11,50 & 11,50 & 9,00 & - \\
Visita ao Veterinário & 4,50 & 4,50 & - & 25,00 \\
Vacinação & 25,00 & 25,00 & 25,00 & 30,00 \\
\hline TOTAL & 85,00 & 35,00 & 50,00 & $\mathbf{2 3 2 , 0 0}$ \\
\hline
\end{tabular}


SOUZA, L. C.; PINHEIRO JÚNIOR, O. A.; MENDONÇA, A. O.; BALLARIS, A. L. Associação homem-animal: reflexos na economia / The association between man and animal: economic repercussions. / Rev. educ. contin. CRMV-SP / Continuous Education Journal CRMV-SP, São Paulo, volume 4, fascículo 1, p. 62 - 65, 2001.

Tabela 3. Número total de cães e gatos e seus respectivos custos de manutenção nos dois primeiros anos de vida. Bauru-SP. 2000.

\begin{tabular}{|l|c|c|c|c|c|c|}
\hline \multicolumn{1}{|c|}{ Espécie } & \multicolumn{3}{|c|}{ Primeiro ano de vida } & \multicolumn{3}{c|}{ Segundo ano de vida } \\
\hline & $\mathbf{n}$ & $\%$ & $\begin{array}{c}\text { Custo de } \\
\text { manutenção } \\
\text { (R\$) }\end{array}$ & $\mathbf{n}$ & $\begin{array}{c}\text { Custo de } \\
\text { manutenção } \\
\text { (R\$) }\end{array}$ \\
\hline Canina & 18.522 & 59,00 & $7.423 .617,60$ & 12.872 & 41,00 & $4.064 .977,60$ \\
\hline Felina & 1.254 & 43,00 & $340.461,00$ & 1.662 & 57,00 & $384.753,00$ \\
\hline
\end{tabular}

riodicamente pela AVMA nos Estados Unidos local, regional e nacionalmente, fornecendo subsídios importantes, não só para as empresas e veterinários, como também para as instituições responsáveis pelo controle da população animal e seu bem-estar (NASSAR e MOSIER, 1991).

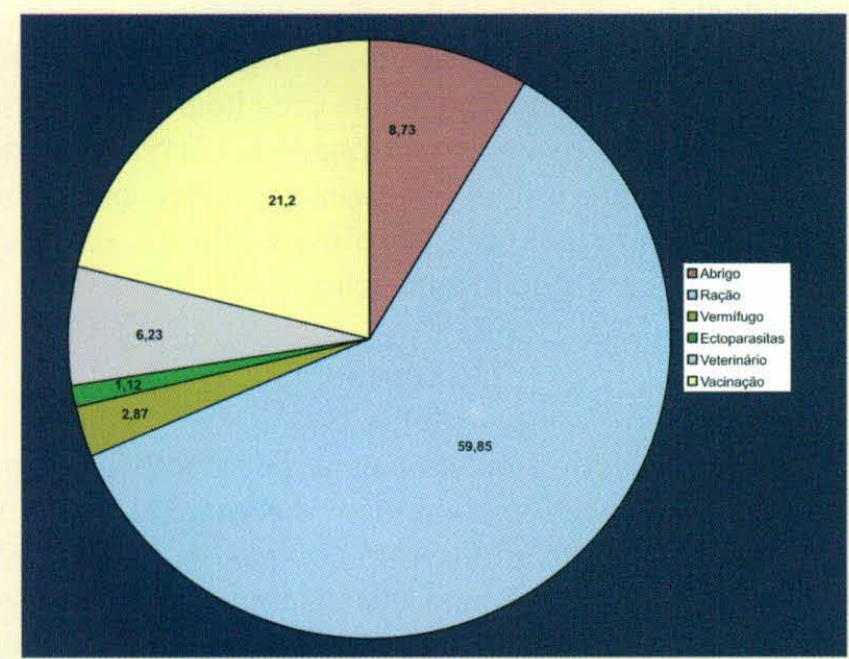

Figura 1. Porcentagem de participação de diferentes itens no cálculo do custo de manutenção ideal de cães no primeiro ano de vida. Bauru-SP. 2000.

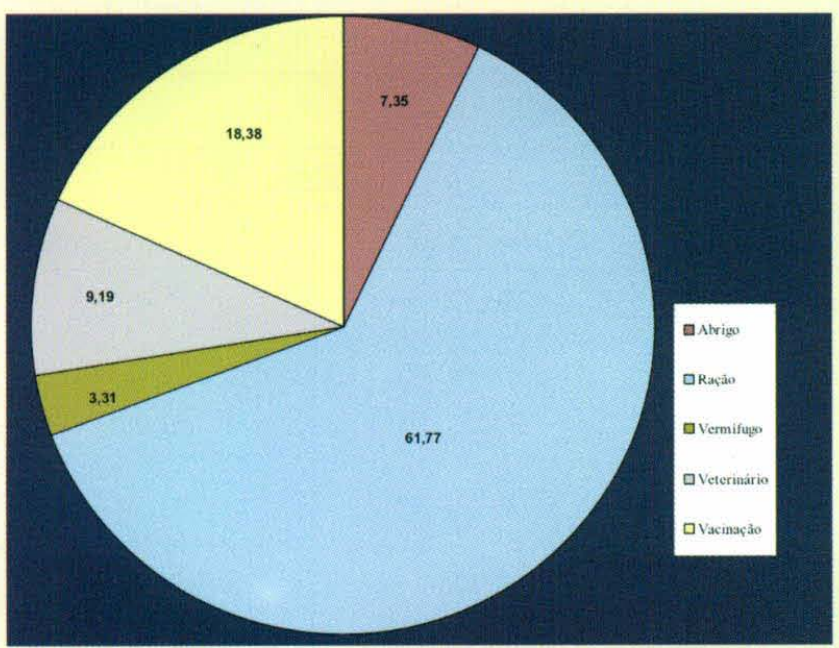

Figura 3. Porcentagem de participação de diferentes itens no cálculo do custo de manutenção ideal de gatos no primeiro ano de vida. Bauru-SP. 2000.
Os resultados obtidos no presente trabalho não podem ser comparados com os resultados das pesquisas realizadas nos Estados Unidos e tampouco extrapolados para outras regiões do País, em virtude das diferenças sócio-econômicas entre elas. No entanto,

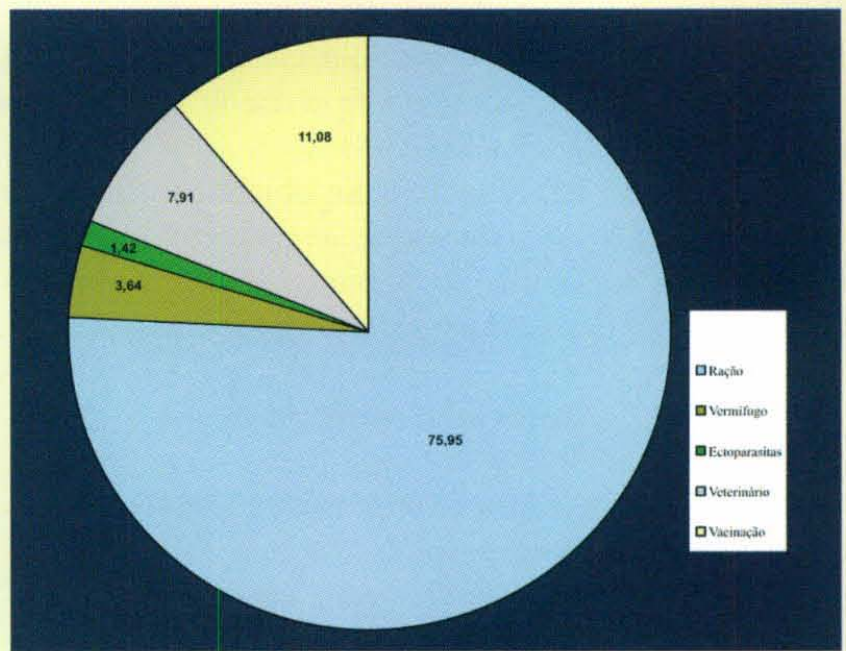

Figura 2. Porcentagem de participação de diferentes itens no cálculo do custo de manutenção ideal de cães no segundo ano de vida. Bauru-SP. 2000.

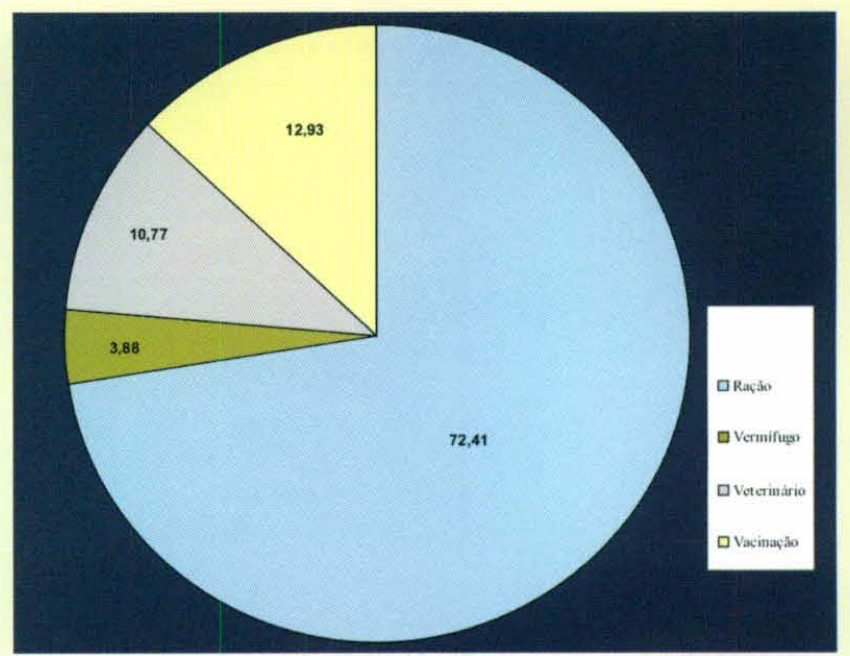

Figura 4. Porcentagem de participação de diferentes itens no cálculo do custo de manutenção ideal de gatos no segundo ano de vida. Bauru-SP. 2000. 
eles nos dão uma idéia do custo que um animal de companhia gera para uma família, quando em condições ideais de manutenção. Os valores obtidos são superiores à capacidade orçamentária de boa parte da população brasileira, o que nos faz crer que a maioria dos proprietários de cães e gatos em nosso País não têm poder aquisitivo suficiente para propiciar condições adequadas de higiene, abrigo e alimentação. Desta forma, os animais de companhia estariam mais sujeitos a adquirir enfermidades, dentre elas, zoonoses bacterianas, parasitárias, virais, entre outras. Algumas delas são de crucial importância para a saúde pública, seja pela alta prevalência, seja pelo elevado grau de letalidade, tais como: leishmaniose, toxoplasmose, leptospirose, larva migrans visceral e cutânea e a raiva (ACHA e SZYFRES, 1992).

Desta forma, deve haver um esforço maior das autoridades e das instituições de ensino para esclarecer à comunidade a respeito do impacto econômico que um animal de estimação pode causar no orçamento familiar e também sobre a importância desses animais enquanto transmissores de importantes doenças para a saúde pública, principalmente quando não recebem os tratos adequados, a fim de popularizar o conceito de posse responsável de animais.

\section{Conclusão}

Mediante a estimativa do custo de manutenção ideal dos cães e gatos no Município de Bauru, verificou-se um valor monetário relativamente alto, quando consideramos a atual situação econômica do País. Apesar dos benefícios ocasionados pelo aquecimento do mercado de "pet shops", principalmente para as empresas do ramo e para a classe médica veterinária, em virtude dos estímulos diretos e indiretos para a obtenção de animais de companhia, em especial cães e gatos, devemos nos preocupar com o bem-estar deles e com a possibilidade de transmissão de doenças, principalmente, quando os cuidados estão aquém do necessário para promover-lhes a saúde.

\section{SUMMARY}

Nowadays, pets represent an important economical support element as, in spite of the financial crisis and high unemployment rates Brazil has to face, the pet shop industry is expanding. Thus, there is direct and indirect encouragement to obtain a pet and strengthen the man-animal relationship. An epidemiological survey was conducted in the municipality of Bauru, state of São Paulo, to study the impact of companion animals on the household and the municipal economy. The study used questionnaires, personal interviews and was also held in veterinary practices, with a total sample of 115 animal owners (91 dogs, 24 cats). Considering the costs involved in the maintenance of pets under ideal conditions (food, drugs, vaccines, veterinary services), the estimated values obtained for the first and second years of life were, respectively, $R \$ 401.00$ and $R \$ 316.00$ for dogs and $R \$ 272.00$ and $R \$$ 232.00 for cats. Authorities and teaching organizations should make a special effort in order to provide the community with information on the economic impact a companion animal can have on a household budget. Information about the importance of these animals from the public health point of view in the transmission of diseases should also be provided. The objective is to make better known the concept of responsible animal ownership.

Key words: pets, market, economy.

\section{REFERÊNCIAS}

1. ACHA, P. N.; SZYFRES, B. Zoonosis y enfermedades transmisibles comunes al hombre y a los animales. 2 ed. Washington: OMS, 1992, 989p.

2. GEHRKE, B. C. Results of the AVMA survey of US pet-owning households on companion animal ownership. Journal of American Veterinary Medical Association, v. 211, n. 2, p. $169-70,1997 \mathrm{a}$.

3. GEHRKE, B. C. Results of the 1997 AVMA survey of US petowning households regarding use of veterinary services and expenditures. Journal of American Veterinary Medical Association, v. 211, n. 4, p. 417-8, 1997b.

4. GEHRKE, B. C. Expenditures of US pet-owning households for veterinary medical products and services purchased from veterinarians, 1987 to 1996 . Journal of American Veterinary Medical Association, v. 212, n. 10, p. 1549-50, 1998.

5. NASSAR, R.; MOSIER, J. Projections of pet populations from census demographic data. Journal of American Veterinary Medical Association, v. 198, n. 7, p. 1157-9, 1991. 